Supporting Information for:

\title{
Qubit Control Limited by Spin-Lattice Relaxation in a Nuclear Spin-Free Iron(III) Complex
}

\author{
Joseph M. Zadrozny ${ }^{\dagger}$ and Danna E. Freedman ${ }^{\dagger}$ \\ ${ }^{\dagger}$ Department of Chemistry, Northwestern University, Evanston, Illinois 60208- \\ 3113
}

Inorg. Chem. 


\section{Table of Contents:}

$\begin{array}{ll}\text { Experimental Details } & \text { S3 }\end{array}$

$\begin{array}{ll}\text { Table S1. Tabulated relaxation time data for } \mathbf{1 a} \text { and } \mathbf{1 b} & \text { S8 }\end{array}$

$\begin{array}{ll}\text { Table S2. Crystallographic details for } 2 . & \text { S9 }\end{array}$

Figure S1. High-frequency, low-temperature CW EPR spectra of $\mathbf{1} \quad \mathbf{S 1 0}$

Figure S2. Variable-power nutations and Fourier transforms for 1a. $\quad$ S11

Figure S3. Variable-power nutations and Fourier transforms for 1b. $\quad \mathbf{S 1 2}$

Figure S4. Variable temperature Hahn-echo decay curves and fits for 1a. S13

Figure S5. Variable temperature Hahn-echo decay curves and fits for 1b. $\quad$ S14

Figure S6. Variable-temperature inversion recovery curves for 1a and 1b S15

Figure S7: Molecular structure of $\left(\mathrm{Ph}_{4} \mathrm{P}\right)_{3}\left[\mathrm{Ga}\left(\mathrm{C}_{5} \mathrm{O}_{5}\right)_{3}\right](2) . \quad$ S16

$\begin{array}{ll}\text { References } & \text { S17 }\end{array}$ 


\section{Experimental Details.}

General Considerations. The salt $\mathrm{K}_{2}\left(\mathrm{C}_{5} \mathrm{O}_{5}\right)^{1}$ was synthesized according to previously published methods. The synthesis of $\left(\mathrm{Ph}_{4} \mathrm{P}-d_{20}\right) \mathrm{Br}^{2}$ proceeded via a slightly modified procedure for the preparation of $\left(\mathrm{Ph}_{4} \mathrm{P}\right) \mathrm{Br}$ from $\mathrm{Ph}_{3} \mathrm{P}, \mathrm{C}_{6} \mathrm{H}_{5} \mathrm{Br}$, and $\mathrm{Pd}_{2}(\mathrm{dba})_{3}$, using $d^{15}-\mathrm{Ph}_{3} \mathrm{P}$ and $\mathrm{C}_{6} \mathrm{D}_{5} \mathrm{Br}$. Distilled water $\left(\mathrm{H}_{2} \mathrm{O}\right)$, methanol $(\mathrm{MeOH})$, dichloromethane $(\mathrm{DCM})$, diethylether $\left(\mathrm{Et}_{2} \mathrm{O}\right)$, $\mathrm{MgSO}_{4}, \mathrm{Na}_{2} \mathrm{SO}_{4},\left(\mathrm{Ph}_{4} \mathrm{P}\right) \mathrm{Br}, \mathrm{Ga}\left(\mathrm{NO}_{3}\right)_{3} \bullet \times \mathrm{H}_{2} \mathrm{O}$, and $\mathrm{FeCl}_{3}\left(\mathrm{H}_{2} \mathrm{O}\right)_{6}$ were either used as received or without further purification.

$\left(\mathrm{Ph}_{4} \mathbf{P}\right)_{3}\left[\mathbf{F e}\left(\mathrm{C}_{5} \mathrm{O}_{5}\right)_{3}\right]$ (1) This compound was prepared by an alternative route from the literature synthesis. ${ }^{3}$ To a solution of $\mathrm{K}_{2}\left(\mathrm{C}_{5} \mathrm{O}_{5}\right)(430 \mathrm{mg}, 1.97 \mathrm{mmol})$ in $\mathrm{H}_{2} \mathrm{O}(20 \mathrm{~mL})$ a solution of $\mathrm{FeCl}_{3}\left(\mathrm{H}_{2} \mathrm{O}\right)_{6}(177 \mathrm{mg}, 0.654 \mathrm{mmol})$ in $\mathrm{H}_{2} \mathrm{O}(4 \mathrm{~mL})$ was added. The dark brown solution was stirred briefly, then solid $\left(\mathrm{Ph}_{4} \mathrm{P}\right) \mathrm{Br}(650 \mathrm{mg}, 1.55 \mathrm{mmol})$ was added, causing instant precipitation of a dark brown solid. The mixture was stirred for $1 \mathrm{~h}$, then filtered. The collected solid was extracted with $80 \mathrm{~mL}$ of DCM to yield a dark purple solution. The purple solution was dried with anhydrous $\mathrm{MgSO}_{4}$, filtered, and evaporated to dryness. The purple residue was

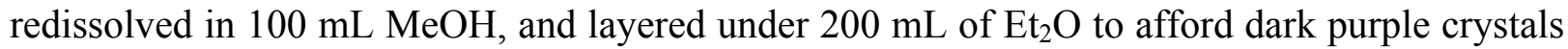
(408 mg, $53 \%$ ) of 1 after several days. Spectroscopic data match previously reported values. ${ }^{3}$ IR ( $\left.\mathrm{cm}^{-1}\right)$ : 2934(w), 2856(w), 1731(w), 1703(w), 1615(s), 1586(w), 1521(w), 1464(vs), 1435(vs), 1349(w), 1190(w), 1108(s), 1076(w), 996(w), 756(m), 722(s), 689(s), 627(m), 549(m), 526(vs), 460(s). Anal. Calcd. (Found) for $\mathrm{C}_{87} \mathrm{H}_{60} \mathrm{FeO}_{15} \mathrm{P}_{3} \cdot 2\left(\mathrm{CH}_{3} \mathrm{OH}\right): 68.60$ (68.28) $\% \mathrm{C}$ and 4.40 (4.02) \%H. PXRD patterns closely follow the powder pattern simulated with the previously reported structure. $^{3}$ 
$\left(\mathbf{P h}_{4} \mathbf{P}\right)_{3}\left[\mathbf{G a}\left(\mathbf{C}_{5} \mathbf{O}_{5}\right)_{3}\right]$ (2) To a yellow solution of $\mathrm{K}_{2}\left(\mathrm{C}_{5} \mathrm{O}_{5}\right)(482 \mathrm{mg}, 2.21 \mathrm{mmol})$ in $\mathrm{H}_{2} \mathrm{O}(20$ $\mathrm{mL})$ a solution of $\mathrm{Ga}\left(\mathrm{NO}_{3}\right)_{3} \cdot \times \mathrm{H}_{2} \mathrm{O}(189 \mathrm{mg}, 0.740 \mathrm{mmol}$ assumed anhydrous $)$ in $\mathrm{H}_{2} \mathrm{O}(10 \mathrm{~mL})$ was added with stirring. The yellow solution was left to stir for $10 \mathrm{~m}$, after which a solution of $\left(\mathrm{Ph}_{4} \mathrm{P}\right) \mathrm{Br}(619 \mathrm{mg}, 1.48 \mathrm{mmol})$ in $\mathrm{H}_{2} \mathrm{O}(20 \mathrm{~mL})$ was added dropwise. The resultant aqueous slurry of yellow precipitate was stirred $1 \mathrm{~h}$, then filtered. The collected solid was extracted with $100 \mathrm{~mL}$ of DCM, dried with anhydrous $\mathrm{MgSO}_{4}$, and evaporated to dryness. The yellow residue was redissolved in $30 \mathrm{~mL}$ of $\mathrm{MeOH}$ and layered under $\mathrm{Et}_{2} \mathrm{O}$. Yellow block crystals of the title compound formed after several days (501 mg, $45 \%$ ). IR ( $\left.\mathrm{cm}^{-1}\right)$ : 2933(w), 2866(w), 1680(w), 1615(s), 1473(s), 1456(vs), 1436(s), 1190(w), 1108(s), 1082(w), 997(w), 756(m), 722(s), 689(s), 631(m), 552(m), 526(vs), 496(m). Anal. Calcd. (Found) for $\mathrm{C}_{87} \mathrm{H}_{60} \mathrm{GaO}_{15} \mathrm{P}_{3} \bullet 2\left(\mathrm{CH}_{3} \mathrm{OH}\right)$ : $67.99(68.59) \% \mathrm{C}$ and $4.36(4.39) \% \mathrm{H}$. The PXRD pattern for a bulk sample closely follows that simulated on the basis of the single-crystal structure.

$\left(\mathbf{P h}{ }_{4} \mathrm{P}-\boldsymbol{d}_{20}\right)_{3}\left[\mathrm{Fe}\left(\mathrm{C}_{5} \mathrm{O}_{5}\right)_{3}\right]\left(\mathbf{1}^{\prime}\right)$ This compound was prepared analogously to $\mathbf{1}$ utilizing $\left(\mathrm{Ph}_{4} \mathrm{P}-\right.$ $\left.d_{20}\right) \mathrm{Br}$ instead of $\left(\mathrm{Ph}_{4} \mathrm{P}\right) \mathrm{Br}$. The PXRD pattern for a microcrystalline sample of this species matches that of $\mathbf{1}$ and $\mathbf{2}$.

$\left(\mathrm{Ph}_{4} \mathbf{P}-\boldsymbol{d}_{20}\right)_{3}\left[\mathbf{G a}\left(\mathrm{C}_{5} \mathrm{O}_{5}\right)_{3}\right]\left(\mathbf{2}^{\prime}\right)$ This compound was prepared analogously to $\mathbf{1}$ utilizing $\left(\mathrm{Ph}_{4} \mathrm{P}-\right.$ $\left.d_{20}\right) \mathrm{Br}$ instead of $\left(\mathrm{Ph}_{4} \mathrm{P}\right) \mathrm{Br}$. The PXRD pattern for a microcrystalline sample of this species matches that of $\mathbf{1}$ and $\mathbf{2}$.

$\left(\mathbf{P h}_{4} \mathbf{P}\right)_{3}\left[\mathbf{F e}_{0.002} \mathbf{G a}_{0.998}\left(\mathbf{C}_{5} \mathbf{O}_{5}\right)_{3}\right]$ (1a) Solid $\left(\mathrm{Ph}_{4} \mathrm{P}\right)_{3}\left[\mathrm{Fe}\left(\mathrm{C}_{5} \mathrm{O}_{5}\right)_{3}\right]\left(0.6 \mathrm{mg}, 4 \times 10^{-4} \mathrm{mmol}\right)$ and $\left(\mathrm{Ph}_{4} \mathrm{P}\right)_{3}\left[\mathrm{Ga}\left(\mathrm{C}_{5} \mathrm{O}_{5}\right)_{3}\right](300 \mathrm{mg}, 0.199 \mathrm{mmol})$ were dissolved with stirring in $40 \mathrm{~mL}$ of $\mathrm{MeOH}$. To this solution, $120 \mathrm{~mL}$ of $\mathrm{Et}_{2} \mathrm{O}$ was added over the course of 1 minute, producing a greenishyellow crystalline precipitate and colorless solution. The PXRD pattern for a bulk microcrystalline sample of this species matches that of $\mathbf{1}$ and $\mathbf{2}$. 
$\left(\mathbf{P h}_{4} \mathbf{P}-d_{20}\right)_{3}\left[\mathbf{F e}_{0.002} \mathbf{G a}_{0.998}\left(\mathbf{C}_{5} \mathbf{O}_{5}\right)_{3}\right](\mathbf{1 b})$ Solid $\left(d^{20}-\mathrm{Ph}_{4} \mathrm{P}\right)_{3}\left[\mathrm{Fe}\left(\mathrm{C}_{5} \mathrm{O}_{5}\right)_{3}\right]\left(0.6 \mathrm{~g}, 4 \times 10^{-4} \mathrm{mmol}\right)$ and $\left(\mathrm{Ph}_{4} \mathrm{P}-d_{20}\right)_{3}\left[\mathrm{Ga}\left(\mathrm{C}_{5} \mathrm{O}_{5}\right)_{3}\right](300 \mathrm{mg}, 0.191 \mathrm{mmol})$ were dissolved with stirring in $40 \mathrm{~mL}$ of $\mathrm{MeOH}$. To this solution, $120 \mathrm{~mL}$ of $\mathrm{Et}_{2} \mathrm{O}$ was added over the course of one minute, producing a greenish-yellow crystalline precipitate and colorless solution. The PXRD pattern for a bulk microcrystalline sample matches that of $\mathbf{1}$ and $\mathbf{2}$.

EPR Measurements. All measurements were performed at the National High Magnetic Field Laboratory (NHMFL) in Tallahassee, Florida. Microcrystalline powders were prepared for analyses by heating at $70{ }^{\circ} \mathrm{C}$ under vacuum for several days. Elemental analyses, IR spectra, and PXRD patterns indicated that this treatment resulted in loss of cocrystallized methanol but not complex decomposition. All pulsed measurements were collected on compacted powder samples. High-frequency, high-field measurements were performed on compacted powders restrained with eicosane. Samples were prepared in plastic caps or $4 \mathrm{~mm}$ O.D. quartz tubes (Wilmad) for measurement.

High-field, high-frequency continuous-wave EPR (CW-EPR) spectra on 1 were collected on an instrument described elsewhere. ${ }^{4}$ Pulsed X-band EPR data were obtained on a Bruker E680 spectrometer equipped with an ER 4118X-MD5 dielectric resonator. Temperature was controlled with an Oxford Instruments CF935 helium flow cryostat and an Oxford Instruments ITC503 temperature controller. Field-swept electron spin echo-detected EPR spectra were recorded using a two-pulse echo sequence $(\pi / 2-\tau-\pi-\tau-$ echo) with microwave (mw) pulse lengths of $12 \mathrm{~ns}$ and $24 \mathrm{~ns}$ and an interpulse time $\tau=120 \mathrm{~ns}$. Echo decay curves were collected by application of the above sequence at the field of maximum echo intensity at variable temperatures using $12 \mathrm{~ns}$ and $24 \mathrm{~ns} \pi / 2$ and $\pi$ pulses, respectively, with varying $\tau$ (starting from $\tau$ $=120 \mathrm{~ns}) \cdot T_{1}$ values were obtained at the main resonances using a three-pulse inversion 
recovery sequence $(\pi-T-\pi / 2-\tau-\pi-\tau-$ echo) with $\tau$ of 120 ns chosen to minimize the effect of electron spin echo envelope modulation by surrounding nuclei. Rabi oscillations were observed via echo detection of the longitudinal magnetization following a variable-length nutation pulse ( $\left.t_{\mathrm{p}}\right)$ with the sequence $\left(t_{\mathrm{p}}-T-\pi / 2-\tau-\pi-\tau-\right.$ echo). The exact pulse sequence varied depending on the attenuation level of $B_{1}$. For $1-2 \mathrm{~dB}$ attenuation, the $\pi / 2$ and $\pi$ pulses used were $12 \mathrm{~ns}$ in length. For 3-4 dB attenuation, the second and third pulses were 16 and $32 \mathrm{~ns}$ in length. Note also that, as for the inversion recovery experiment, $\tau$ was chosen to maximize echo intensity as required due to the extensive ESEEM observed in the 2-pulse Hahn echo experiment.

Spectral Data Analysis. Spectral data workup was performed using Xepr ${ }^{5}$, Origin $^{6}$, Excel $^{7}$ and Matlab. ${ }^{8} \mathrm{CW}$ spectra were analysed with Easyspin. ${ }^{9}$ Inversion recovery data were normalized and fit with stretched exponential recovery functions. Coherence times $\left(T_{2}\right)$ were obtained from normalized data and only the peak maxima were fit to a stretched exponential decay, as depicted in Figs. 4, S4, and S5.

X-ray Diffraction Studies. Powder X-ray diffraction (PXRD) patterns were collected with a Panalytical Empyrean diffractometer using $\mathrm{Cu} \mathrm{K \alpha}(\lambda=1.54178 \AA)$ radiation and a PIXcel1D detector. PXRD patterns were simulated with Mercury $^{10}$ on the basis of single crystal structures of pure $\mathbf{1}^{3}$ and $\mathbf{2}$. Single crystals of $\mathbf{2}$ suitable for X-ray analysis were coated with Paratone $\mathrm{N}$ oil and mounted on a MiTeGen MicroLoop ${ }^{\mathrm{TM}}$ for analysis. Crystallographic data were collected at $100 \mathrm{~K}$ on a Bruker KAPPA APEX diffractometer equipped with a microfocus CuK $\alpha$ sealed tube diffraction source and MX Optics monochromator, and a Bruker APEX II detector. Raw data were integrated and corrected for Lorentz and polarization effects using Bruker Apex2 v. 2013.2. ${ }^{11}$ Absorption corrections were applied using SADABS. ${ }^{12}$ Space group assignments were determined by examination of systematic absences, E-statistics, and successive refinement of 
the structures. Structures were solved using direct methods in SHELXS and further refined with SHELXL-2013 ${ }^{13}$ operated with the OLEX2 interface. ${ }^{14}$ Crystallographic data and the details of data collection are listed in Table S2, and the structure can be accessed at the Cambridge Structural Database with accession code CCDC 1427401.

Other Physical Measurements. Elemental analyses were performed by Midwest Micro lab, llc. IR spectra were recorded on crushed single crystals with a Bruker Alpha FTIR spectrometer equipped with an attenuated total reflectance accessory. 
Table S1| Relaxation time data for $\mathbf{1 a}$ and $\mathbf{1 b .}$

\begin{tabular}{|c|c|c|c|c|c|c|c|c|}
\hline \multirow[b]{2}{*}{$T(\mathrm{~K})$} & \multicolumn{4}{|c|}{$1 \mathrm{a}$} & \multicolumn{4}{|c|}{$1 b$} \\
\hline & $T_{1}(\mu \mathrm{s})$ & $\beta$ & $T_{2}(\mathrm{~ns})$ & $\beta$ & $T_{1}(\mu \mathrm{s})$ & $\beta$ & $T_{2}(\mathrm{~ns})$ & $\beta$ \\
\hline 5 & $11.32(1)$ & $0.67(1)$ & $721(7)$ & $0.74(1)$ & $7.99(2)$ & $0.71(1)$ & $1596(10)$ & $1.22(3)$ \\
\hline 7 & $7.09(3)$ & $0.66(1)$ & $633(10)$ & $0.83(1)$ & $4.15(2)$ & $0.72(1)$ & $944(12)$ & $0.93(2)$ \\
\hline 9 & $3.51(1)$ & $0.69(1)$ & $536(7)$ & $0.88(1)$ & $2.241(7)$ & $0.75(1)$ & $600(14)$ & $0.70(2)$ \\
\hline 10 & - & - & - & - & $1.852(8)$ & $0.77(1)$ & - & - \\
\hline 11 & $1.86(1)$ & $0.73(1)$ & $439(14)$ & $0.81(2)$ & $1.547(5)$ & $0.81(1)$ & - & - \\
\hline 13 & $1.31(1)$ & $0.76(1)$ & $363(8)$ & $0.90(2)$ & $1.081(5)$ & $0.80(1)$ & - & - \\
\hline 15 & $1.18(1)$ & $0.75(1)$ & $336(8)$ & $0.93(1)$ & $0.821(7)$ & $0.80(1)$ & - & - \\
\hline
\end{tabular}


Table S2 | Crystallographic information for the structural refinement of 2.

\begin{tabular}{ll}
\hline Empirical Formula & $\mathrm{C}_{89} \mathrm{H}_{68} \mathrm{GaO}_{17} \mathrm{P}_{3}$ \\
Formula weight & $1572.06 \mathrm{~g} / \mathrm{mol}$ \\
Temperature & $100(2) \mathrm{K}$ \\
Wavelength & $1.54178 \AA$ \\
Crystal System & Monoclinic \\
Space Group & $P 2_{1} / \mathrm{n}$ \\
Unit Cell Dimensions & $a=12.6901(12) \AA, \alpha=90^{\circ}$ \\
& $b=18.1961(17) \AA, \beta=90.033(2)^{\circ}$ \\
& $c=32.254(3) \AA, \gamma=90^{\circ}$ \\
Volume & $7447.8(12) \AA^{3}$ \\
$Z$ & 4 \\
Density (calculated) & $1.402 \mathrm{Mg} / \mathrm{m}^{3}$ \\
Absorption coefficient & $1.721 \mathrm{~mm}{ }^{-1}$ \\
$F_{000}$ & 3256 \\
Crystal color & Yellow \\
Crystal size & $0.25 \cdot 0.13 \cdot 0.09 \mathrm{~mm}^{3}$ \\
$2 \theta$ range & 5.58 to $130.86^{\circ}$ \\
Index ranges & $-14 \leq h \leq 14$ \\
& $-21 \leq k \leq 21$ \\
Reflections collected & $-32 \leq l \leq 37$ \\
Independent reflections & 62102 \\
Completeness to $2 \theta=130.86^{\circ}$ & $12280\left[R_{\text {int }}=0.0222\right]$ \\
Absorption correction & $98.7 \%$ \\
Maximum and minimum transmission & Multi-scan \\
Refinement method & 0.689 and 0.753 \\
Data / restraints / parameters & Full-matrix least-squares on F $\mathrm{F}^{2}$ \\
Goodness-of-fit on $\mathrm{F}^{2 a}$ & $12280 / 0 / 996$ \\
Final $R$ indices $[\mathrm{I}>2 \sigma(\mathrm{I})=10673 \text { data }]^{b}$ & 1.090 \\
$R$ indices (all data, $0.80 \AA)$ & $R_{1}=3.24 \%, w R_{2}=8.69 \%$ \\
Largest diff. peak and hole $^{\circ}$ & $R_{1}=3.38 \%, w R_{2}=9.22 \%$ \\
\hline
\end{tabular}

${ }^{a} \mathrm{GooF}=\left[\Sigma\left[w\left(F_{\mathrm{o}}^{2}-F_{\mathrm{c}}{ }^{2}\right)^{2}\right] /(\mathrm{n}-\mathrm{p})\right]^{1 / 2}$ where $\mathrm{n}$ is the number of reflections and $\mathrm{p}$ is the total number of parameters refined. ${ }^{b} R_{1}=\Sigma|| F_{\mathrm{o}}|-| F_{\mathrm{c}}|| / \Sigma\left|F_{\mathrm{o}}\right| ; w R_{2}=\left[\Sigma\left[w\left(F_{\mathrm{o}}{ }^{2}-F_{\mathrm{c}}{ }^{2}\right)^{2}\right] / \Sigma\left[w\left(F_{\mathrm{o}}{ }^{2}\right)^{2}\right]\right]^{1 / 2}$ 

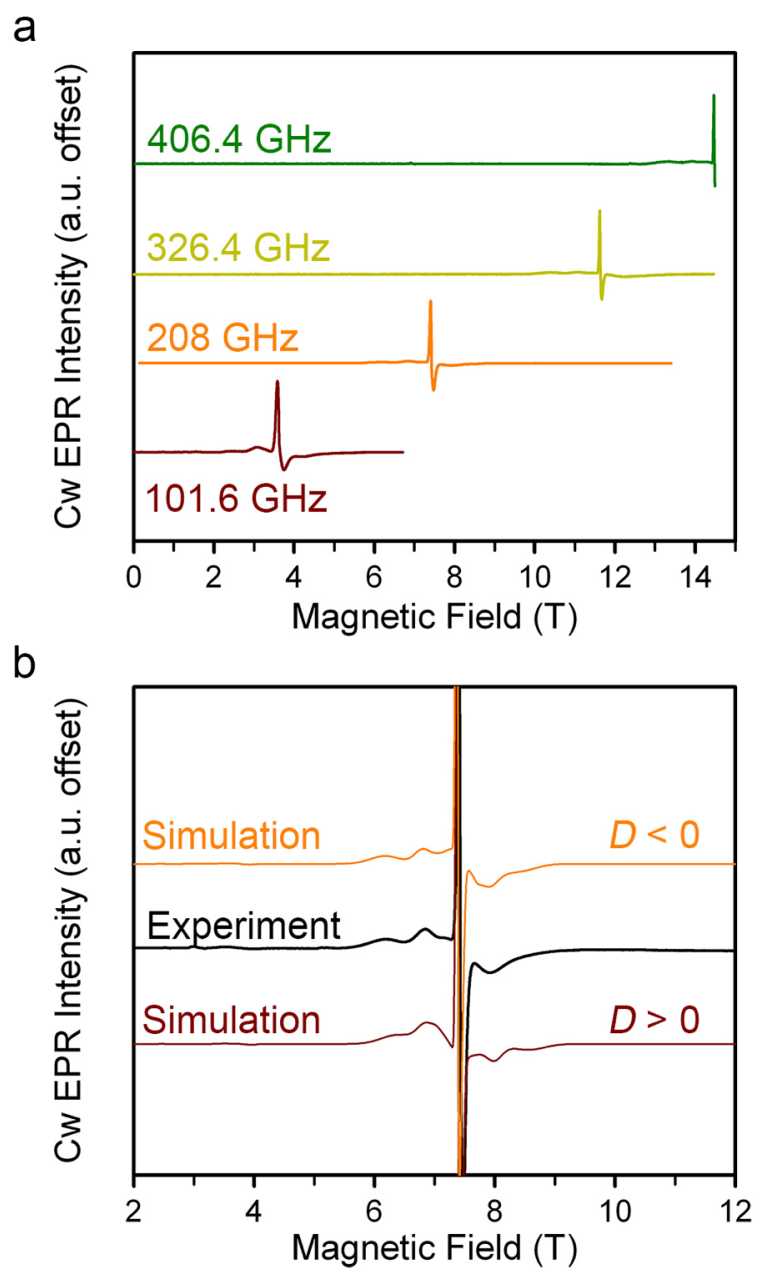

Figure S1 | a. High frequency EPR spectra for 1 at $5 \mathrm{~K}$. b. Best spectral simulations of the 208 $\mathrm{GHz}, 5 \mathrm{~K}$ spectrum with negative and positive $D$ values. Parameters for $D<0$ simulation: $g_{\mathrm{x}}=$ $2.009, g_{\mathrm{y}}=2.010, g_{\mathrm{z}}=2.011, D=-0.30 \mathrm{~cm}^{-1},|E|=0.07 \mathrm{~cm}^{-1} ; D>0 g_{\mathrm{x}}=2.009, g_{\mathrm{y}}=2.010, g_{\mathrm{z}}=$ $2.011, D=+0.30 \mathrm{~cm}^{-1},|E|=0.07 \mathrm{~cm}^{-1}$. Broadening was accounted for by using $D$ strain values of [4000 2500]. No change in the spectral simulation is observed for changing the sign of $E$; thus the values reported are absolute. 

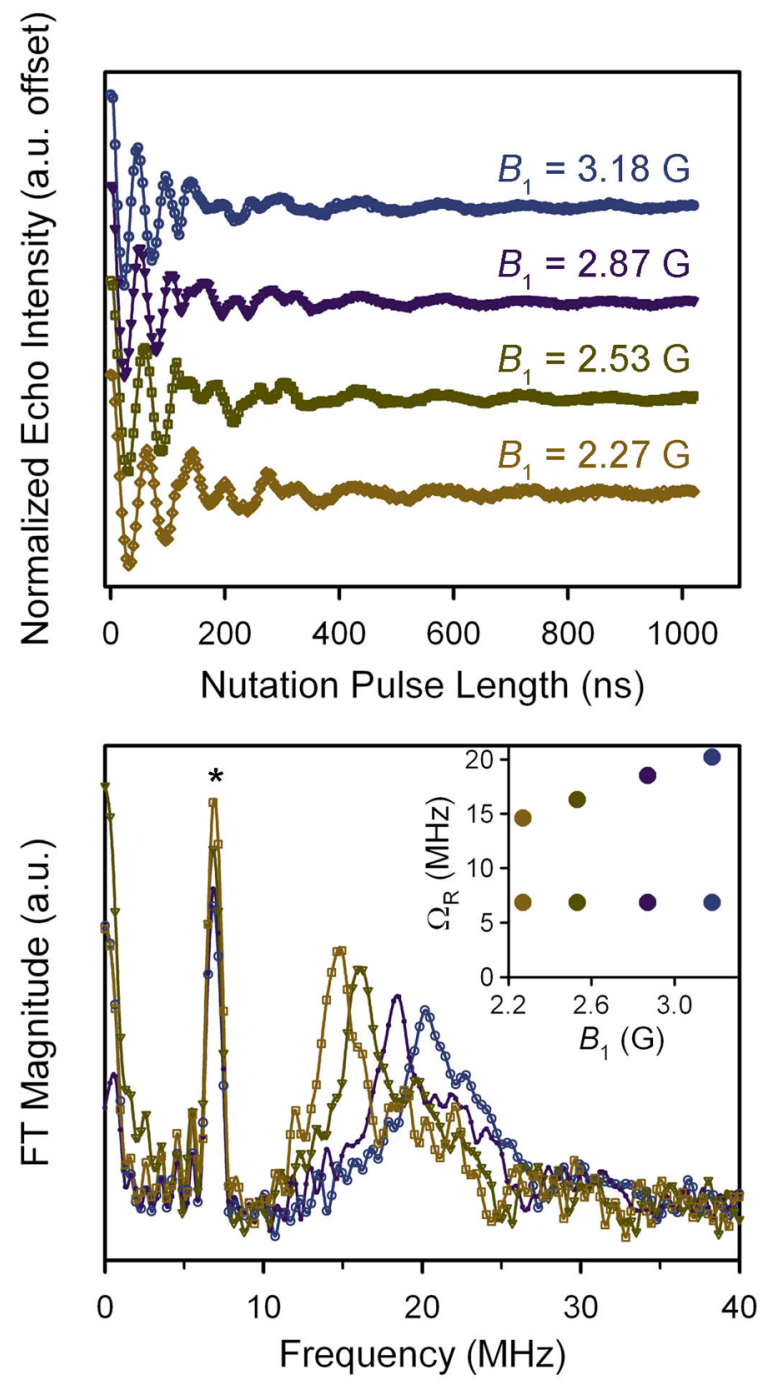

Figure S2 | Variable-power nutations for 1a at $10 \mathrm{~K}$ and $H_{\mathrm{dc}}=1608 \mathrm{G}$ (top). Irregularities in the nutations after $100 \mathrm{~ns}$, as well as the persistent oscillation at times greater than $400 \mathrm{~ns}$, are from the Hartman-Hahn effect. The Fourier transforms of the nutation data (bottom) thus depict two peaks; the one which changes with $B_{1}$ corresponds to the nutating spin. The one which does not move is at $6.83 \mathrm{MHz}$, which corresponds to the Larmor frequency of ${ }^{1} \mathrm{H}$ at $1608 \mathrm{G}$. 

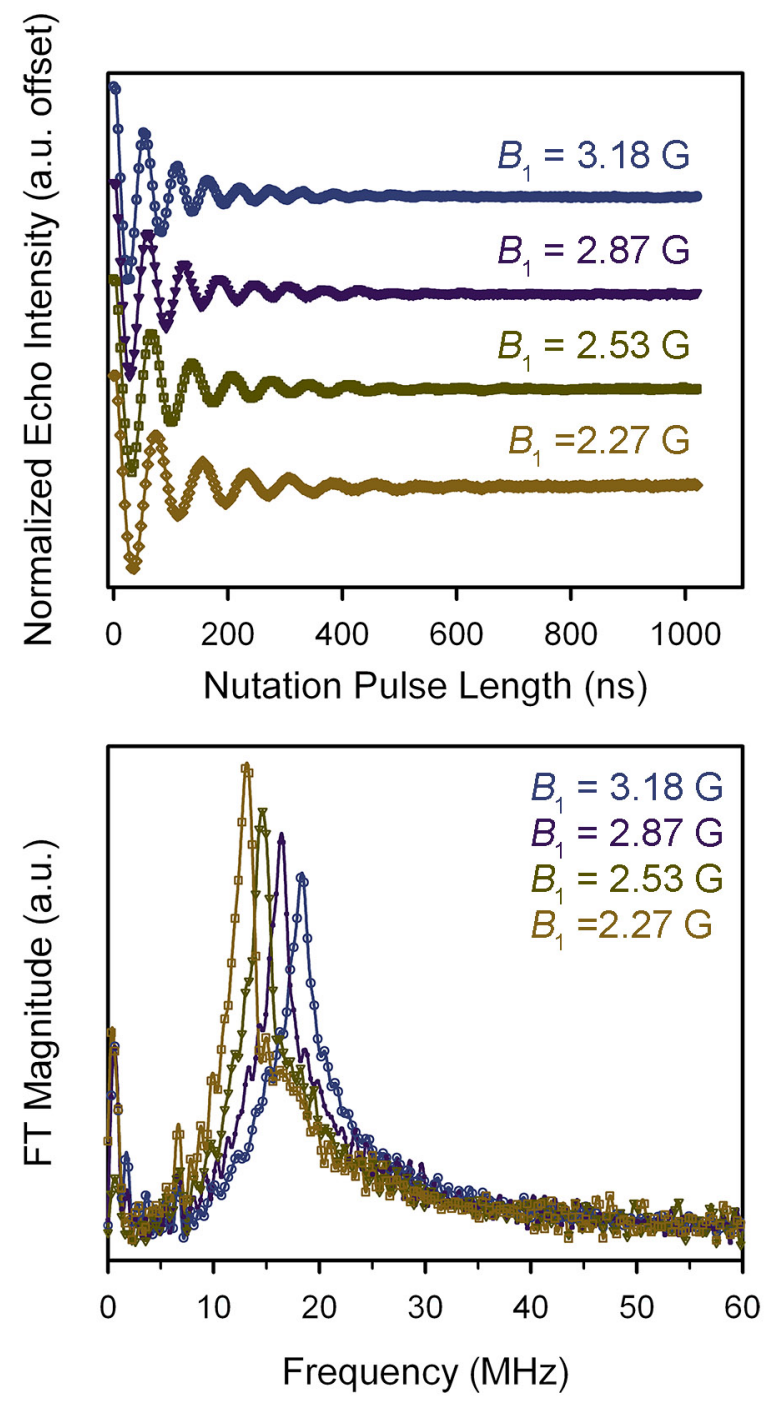

Figure S3 | Variable-power echo-detected nutations for $\mathbf{1 b}$ at $10 \mathrm{~K}$ and $1648 \mathrm{G}$ (top). $B_{1}$ values are indicated next to each data set. Fourier transforms of the nutation data (bottom). Frequencies for the maximum in each data set are depicted in the inset of Fig. 3 of the main text. 

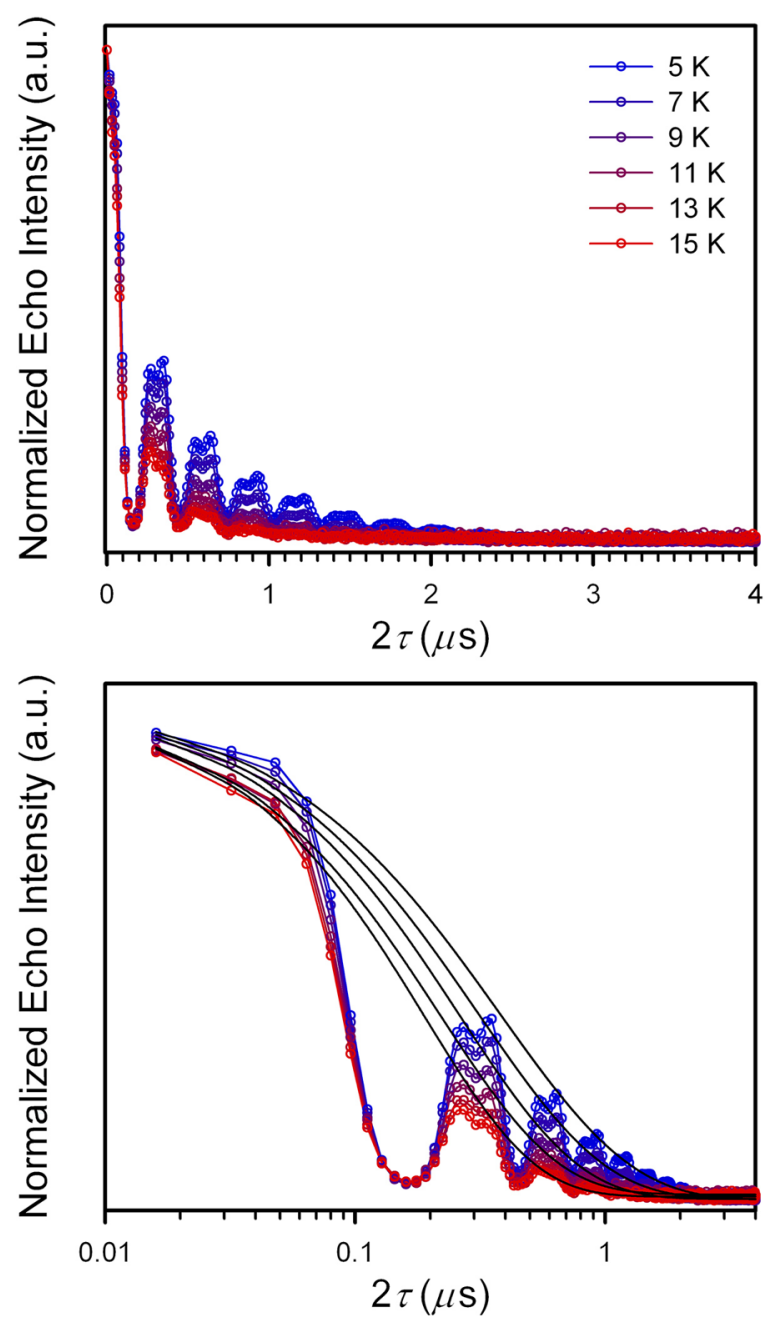

Figure S4 | Variable-temperature echo-decay curves for 1a from 5 to $15 \mathrm{~K}$. Data are plotted logarithmically in the time-domain in the bottom graph for clarity. Black lines are fits to a stretched exponential function. 


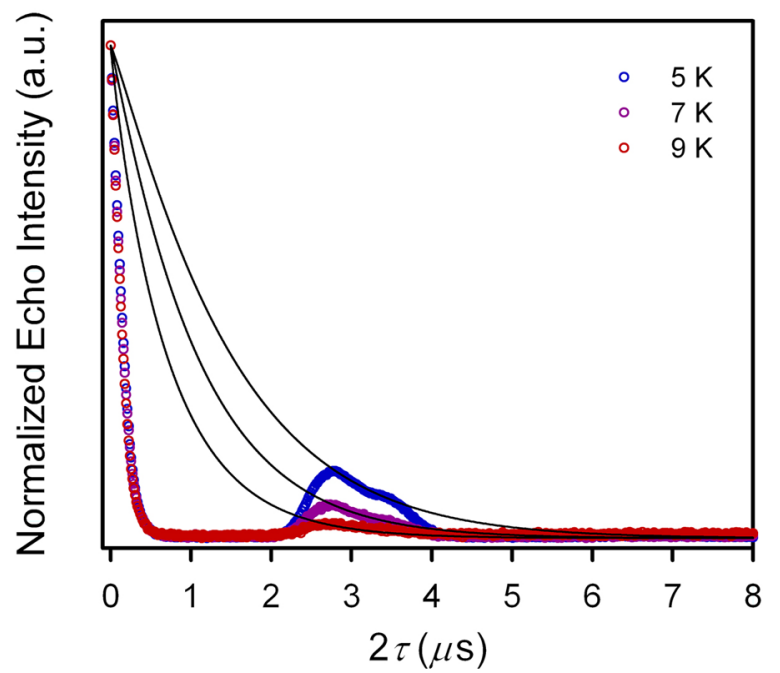

Figure S5 | Variable-temperature echo-decay curves for $\mathbf{1 b}$ at 5, 7, and $9 \mathrm{~K}$. Black lines are fits to a stretched exponential function. 

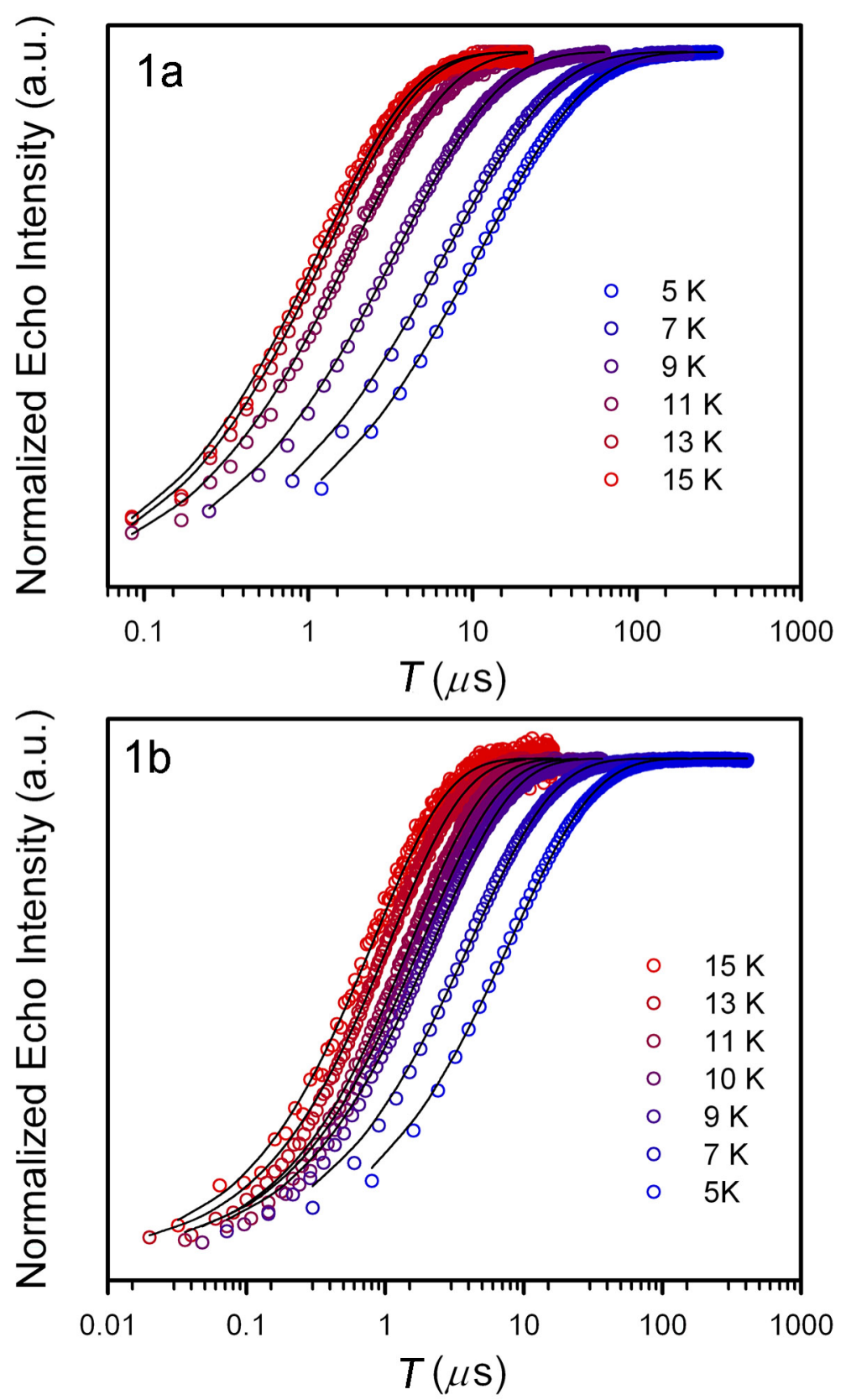

Figure S6 | Variable-temperature inversion recovery data for 1a (top) and 1b (bottom). Black lines are best fits to stretched exponential recoveries. 


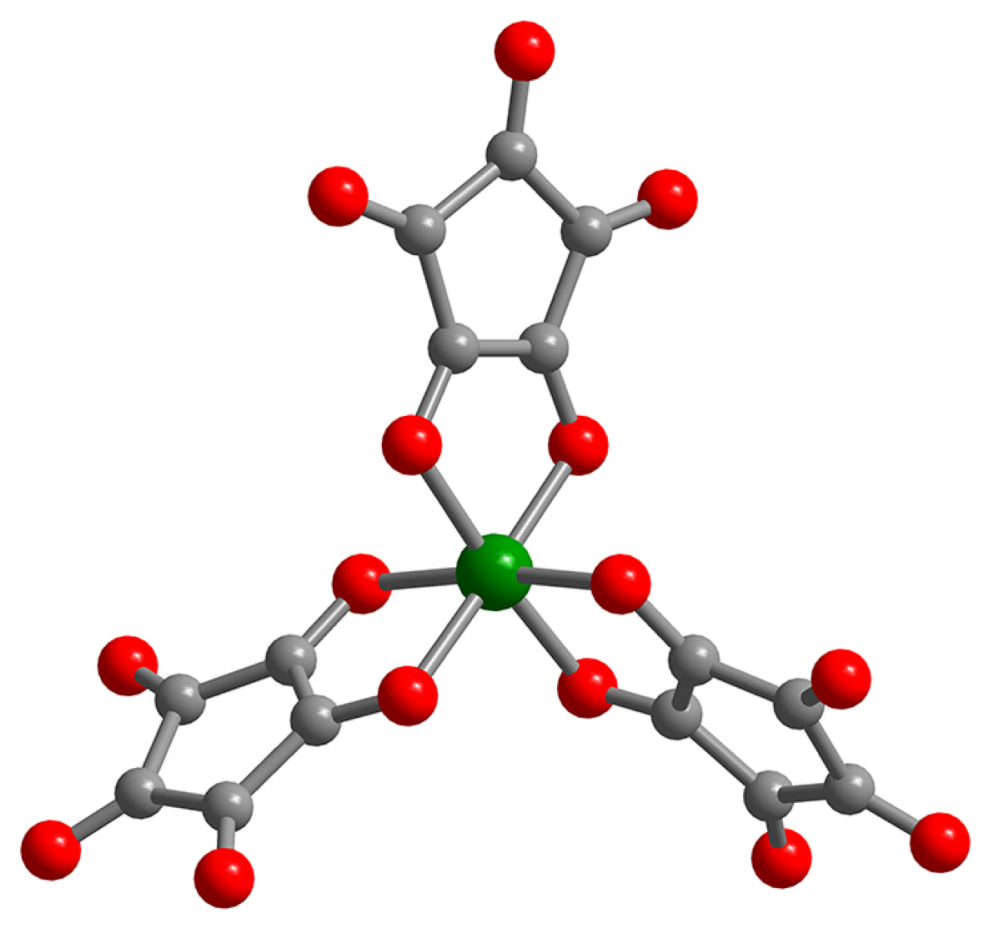

Figure S7 | Molecular structure of $\left[\mathrm{Ga}\left(\mathrm{C}_{5} \mathrm{O}_{5}\right)_{3}\right]^{3-}$ as occurs in the structure of 2. Green, gray, and red spheres are gallium, carbon, and oxygen atoms, respectively. Counterions and cocrystallized solvent molecules have been omitted for clarity. 


\section{$\underline{\text { References }}$}

(1) Williams, R. F. X. Phosphorus, Sulfur Silicon Relat. Elem. 1976, 2, 141-146.

(2) Marcoux, D.; Charette, A. B. J. Org. Chem. 2008, 73, 590-593.

(3) Curreli, S.; Deplano, P.; Faulmann, C.; Mercuri, M. L.; Pilia, L.; Serpe, A.; Coronado, E.; Gómez-García, C. J. Inorg. Chim. Acta. 2006, 359, 1177-1183.

(4) Hassan, A. K.; Pardi, L. A.; Krzystek, J.; Sienkiewicz, A.; Goy, P.; Rohrer, M.; Brunel, L.-C. J. Magn. Reson. 2000, 142, 300-312.

(5) Xepr; Bruker Biospin, Billerica, MA, United States.

(6) Origin; OriginLab, Northampton, MA, United States.

(7) Microsoft Excel; Microsoft, Redmond, WA, United States.

(8) Matlab 12b; The MathWorks, Inc., Natick, MA, United States.

(9) Stoll, S.; Schweiger, A. J. Magn. Reson. 2006, 178, 42-55.

(10) Macrae, C. F.; Bruno, I. J.; Chisholm, J. A.; Edgington, P. R.; McCabe, P.; Pidcock, E.; Rodriguez-Monge, L.; Taylor, R.; van de Streek, J.; Wood, P. A. J. Appl. Cryst. 2008, 41, 466-470.

(11) APEX2, v. 2009 ; Bruker Analytical X-Ray Systems, Inc: Madison, WI, 2009.

(12) Sheldrick, G. M. SADABS, Version 2.03; Bruker Analytical X-Ray Systems, Inc.: Madison, WI, 2000.

(13) Sheldrick, G. M. SHELXTL, Version 6.12; Bruker Analytical X-ray Systems, Inc.: Madison, WI, 2000.

(14) Dolomanov, O. V.; Bourhis, L. J.; Gildea, R. J.; Howard, J. A. K.; Puschmann, H. J. Appl. Cryst. 2009, 42, 339-341. 